\title{
Upregulation of Calcium/Calmodulin-Dependent Protein Kinase IV Improves Memory Formation and Rescues Memory Loss with Aging
}

\author{
Hotaka Fukushima, ${ }^{1}$ Ryouta Maeda, ${ }^{1}$ Ryousuke Suzuki, ${ }^{1}$ Akinobu Suzuki, ${ }^{1}$ Masanori Nomoto, ${ }^{1}$ Hiroki Toyoda, ${ }^{2}$ \\ Long-Jun Wu, ${ }^{2}$ Hui Xu, ${ }^{2}$ Ming-Gao Zhao, ${ }^{2}$ Kenji Ueda, ${ }^{1}$ Aya Kitamoto, ${ }^{1}$ Nori Mamiya, ${ }^{1}$ Taro Yoshida, ${ }^{1}$ Seiichi Homma, ${ }^{1}$ \\ Shoichi Masushige, ${ }^{1}$ Min Zhuo, ${ }^{2}$ and Satoshi Kida ${ }^{1,3}$ \\ ${ }^{1}$ Department of Bioscience, Faculty of Applied Bioscience, Tokyo University of Agriculture, Tokyo 156-8502, Japan, ${ }^{2}$ Department of Physiology, Faculty of \\ Medicine, University of Toronto, Toronto, Ontario, Canada M5S 1A8, and ${ }^{3}$ Core Research for Evolutional Science and Technology, Japan Science and \\ Technology Agency, Saitama 332-0012, Japan
}

Previous studies have suggested that calcium/calmodulin-dependent protein kinase IV (CaMKIV) functions as a positive regulator for memory formation and that age-related memory deficits are the result of dysfunctional signaling pathways mediated by cAMP response element-binding protein (CREB), the downstream transcription factor of CaMKIV. Little is known, however, about the effects of increased CaMKIV levels on the ability to form memory in adult and aged stages. We generated a transgenic mouse overexpressing CaMKIV in the forebrain and showed that the upregulation of CaMKIV led to an increase in learning-induced CREB activity, increased learningrelated hippocampal potentiation, and enhanced consolidation of contextual fear and social memories. Importantly, we also observed reduced hippocampal CaMKIV expression with aging and a correlation between CaMKIV expression level and memory performance in aged mice. Genetic overexpression of CaMKIV was able to rescue associated memory deficits in aged mice. Our findings suggest that the level of CaMKIV expression correlates positively with the ability to form long-term memory and implicate the decline of CaMKIV signaling mechanisms in age-related memory deficits.

Key words: aging; CaMKIV; hippocampus; memory consolidation; transgenic mice; CREB

\section{Introduction}

Memory consolidation is a process in which short-term memory (STM) is stabilized to long-term memory (LTM) (Davis and Squire, 1984; Martin et al., 2000; McGaugh, 2000). The critical biochemical feature of this process is a requirement for the new gene expression (Davis and Squire, 1984; Silva et al., 1998; Martin et al., 2000; McGaugh, 2000). Consistent with this, it is clear that late-phase long-term potentiation, which is proposed to be the cellular mechanism for LTM formation, also requires gene expression (Bliss and Collingridge, 1993; Nguyen et al., 1994; Huang et al., 1996; Martin et al., 2000).

Received June 9, 2008; revised Aug. 2, 2008; accepted Aug. 18, 2008.

This work was supported by Grant-in-Aids for Scientific Research 20380078 and 20658035, and High Technology Research and Priority Areas (Molecular Brain Science) 18022038 and 20022039 from the Ministry of Education, Culture, Sports, Science, and Technology, Japan; Core Research for Evolutional Science and Technology, Japan; and the Research Grant for Nervous and Mental Disorders from the Ministry of Health, Labour, and Welfare, Japan (S.K.). M.Z. is supported by Canadian Institutes of Health Research (CIHR) Grant CIHR84256, the ELLB-CIHR Michael Smith Chair in Neurosciences and Mental Health, and the Canada Research Chair. L.-J.W. is supported by postdoctoral fellowships from CIHR and FragileX Research Foundation of Canada. We thank Dr. Anthony R. Means for providing us with plasmid encoding wild-type CaMKIV.

Correspondence should be addressed to either of the following: Min Zhuo, Department of Physiology, Faculty of Medicine, University of Toronto, 1 King's College Circle, University of Toronto, Toronto, Canada M5S 1A8, E-mail: min.zhuo@utoronto.ca; or Satoshi Kida, Department of Bioscience, Faculty of Applied Bioscience, Tokyo University of Agriculture, 1-1-1 Sakuragaoka, Setagaya-ku, Tokyo 156-8502, Japan, E-mail: kida@nodai.ac.jp.

DOI:10.1523/JNEUROSCI.2625-08.2008

Copyright $\odot 2008$ Society for Neuroscience $\quad$ 0270-6474/08/289910-10\$15.00/0
Activity-dependent gene expression through activation of $\mathrm{Ca}^{2+}$ signaling pathways has been thought to play a central role in memory consolidation and long-term potentiation (LTP) (Nguyen et al., 1994; Silva et al., 1998; Martin et al., 2000). Increases in intracellular concentration of $\mathrm{Ca}^{2+}$ activate a serine threonine kinase calcium/calmodulin-dependent protein kinase IV (CaMKIV) (Jensen et al., 1991; Mathews et al., 1994; Nakamura et al., 1995). Activated CaMKIV phosphorylates transcription factor CAMP response element-binding protein (CREB) at serine 133 (S133) (Jensen et al., 1991; Mathews et al., 1994; Nakamura et al., 1995; Bito et al., 1996; Silva et al., 1998). Phosphorylated CREB at S133 interacts with the transcription coactivator CREB-binding protein (CBP), resulting in the activation of CRE (cAMP response element)-mediated transcription through the recruitment of CBP to the promoter of CREB target genes (Chrivia et al., 1993; Bito et al., 1996; Chawla et al., 1998; Silva et al., 1998; Impey et al., 2002). Interestingly, recent studies have shown that CaMKIV also phosphorylates CBP and enhance its activity (Chawla et al., 1998; Impey et al., 2002). Thus, CaMKIV regulates CREB-CBP-mediated transcription through their phosphorylation, acting as a key mediator of $\mathrm{Ca}^{2+}$ signalstimulated transcription activation.

Aging naturally impairs the ability for learning and memory. Age-related hippocampus-dependent memory deficits have been observed across several species including rodents and humans 
(Barnes, 1979; Perlmutter et al., 1981; Uttl and Graf, 1993; Gallagher and Rapp, 1997; Bach et al., 1999; Erickson and Barnes, 2003; Mouravlev et al., 2006). Importantly, recent studies postulate that age-related dysfunction of the CREB signaling pathway is implicated with an age-related decline in the ability to form memory (Brightwell et al., 2004; Mouravlev et al., 2006).

Importantly, genetic deletion or the inhibition of CaMKIV leads to deficits in both memory formation and LTP (Ho et al., 2000; Kang et al., 2001; Wei et al., 2002). Furthermore, blocking CREB or CBP activity disrupts memory consolidation and impairs certain forms of LTP (Bourtchuladze et al., 1994; Kida et al., 2002; Pittenger et al., 2002; Alarcón et al., 2004; Korzus et al., 2004). Thus, loss of function in CaMKIV-CREB-CBP pathway results in the impairment of certain forms of memory. Therefore, it was proposed that CaMKIV functions as a positive molecular switch to form memory. However, little is known about whether increased levels of CaMKIV can improve the ability to form memory in adult and aged stages. In this current study, we generated transgenic mice overexpressing CaMKIV in the forebrain and examined effects of upregulated CaMKIV expression on memory formation.

\section{Materials and Methods}

Mice. Mice were housed in cages of five or six, maintained on a $12 \mathrm{~h}$ light/dark schedule and allowed ad libitum access to food and water in their home cages. All experiments were conducted during the light phase of the cycle in an illuminated testing room, according to the Guide for the Care and Use of Laboratory Animals, Japan Neuroscience Society, and Tokyo University of Agriculture. All experiments were conducted blind to the treatment condition of the mouse. Animal behavior was recorded using a video camera.

Generation of transgenic mice. To introduce restriction EcoRV and $M l u I$ restriction sites at the $5^{\prime}$ and $3^{\prime}$ ends of CaMKIV coding region and kozak and FLAG-tag sequences followed by an initiation codon, cDNA encoding CaMKIV was amplified by PCR using a plasmid encoding wildtype (WT) CaMKIV (kindly provided by Dr. Anthony R. Means, Duke University School of Medicine, Durham, NC) as a template along with the following primers: forward primer, GGGGATATCGCCGCCACCATGGACTACAAGGACGACGATGACAAACTCAAAACGCGTCTCAAAGTCACGGTGCCC, and reverse primer, GGGGATATCACGCGTTTAGTACTCTGGCAGGATC. The resulting fragment was ligated with a $12.5 \mathrm{~kb} E c o \mathrm{RV}$ fragment containing $\alpha$ CaMKII promoter, a hybrid intron in the $5^{\prime}$ untranslated leader and the SV40 polyadenylation signals from pMM-403-LBDG521R-CREBS133A (Kida et al., 2002), generating a new construct, pMM-403-CaMKIV. The transgene contained an $\alpha$ CaMKII promoter, a hybrid intron in the $5^{\prime}$ untranslated leader, the coding region of CaMKIV and a SV40 polyadenylation [poly(A)] signal. pMM-403-CaMKIV was digested with $S f i$ and transgenic mice were generated by injecting the purified insert into the pronuclei of C57BL/6N zygotes. The CaMKIV founder was crossed with C57BL/6N mice (Charles River). Genotyping was performed by Southern blot analysis using a probe derived from a 1.1 $\mathrm{kb}$ fragment produced by EcoRV/NotI digestion [SV40 poly(A) probe] from pNN-265-LBDG521R-CREBS133A (Kida et al., 2002).

Northern blot analysis. Northern blotting was performed as described previously (Kida et al., 2002) using a ${ }^{32} \mathrm{P}$-labeled SV40 poly(A) probe.

In situ hybridization analysis. In situ hybridization was performed as previously described (Uchida et al., 2006) using a DIG-labeled SV40 poly(A) probe.

Western blot analysis. Hippocampus extracts were prepared as described previously (Kida et al., 2002). Western blotting, using a rabbit polyclonal anti-FLAG epitope Tag antibody (1:1000; Affinity Bioreagents), anti-CREB antibody (1:1000; Cell Signaling Technology), antiphospho-CREB antibody (1:1000; Cell Signaling Technology), a mouse anti-CaMKIV antibody (1:5000; Transduction Laboratories), and an anti- $\alpha$-tubulin antibody (1:1000; Santa Cruz Biotechnology) were performed as described previously (Hosoda et al., 2004). Positive antibody binding was visualized using ECL chemiluminescence (GE Healthcare), and membranes were analyzed with the Lumi-imager TM chemiluminesscence detection system (Roche Diagnostics). The amount of protein in lanes was confirmed to be comparable by reprobing with anti- $\alpha-$ tubulin antibody.

Measurement of CREB activation. To analyze learning-induced CREB activation in CAl tissue, mice were anesthetized 30 min after contextual fear conditioning. Brain tissue was removed immediately after rapid decapitation and immersed in oxygenated $\left(95 \% \mathrm{O}_{2}\right.$ and $\left.5 \% \mathrm{CO}_{2}\right)$ ice-cold artificial CSF (ACSF) containing the following (in mM): $124 \mathrm{NaCl}, 2.5$ $\mathrm{KCl}, 2.5 \mathrm{CaCl}_{2}, 1.3 \mathrm{MgSO}_{4}, 26.2 \mathrm{NaHCO}_{3}, 1 \mathrm{NaH}_{2} \mathrm{PO}_{4}$, and 11 glucose. Transverse dorsal hippocampus slices $(800 \mu \mathrm{m})$ were cut using a vibratome. To isolate the CA1 area from brain tissue samples, slices were frozen quickly on to a glass slide on dry ice and the CA1 area dissected away from other hippocampal subfields under a microscope, as described previously (Watabe et al., 2000). The isolated CA1 regions were homogenized by sonication, and Western blotting was performed. CREB activity (relative phospho-CREB/CREB levels) was calculated by normalizing the level of phosphorylated CREB to the total CREB. Phosphorylated CREB ( $\mathrm{pCREB}$ )/CREB data for each group were expressed as a ratio of the mean values observed in the wild-type-conditioned stimulus (CS)-only control group.

Contextual fear conditioning. Mice were trained and tested in conditioning chambers $(17.5 \times 17.5 \times 15 \mathrm{~cm})$ fitted with a stainless-steel grid floor through which footshocks could be delivered as previously described (Kida et al., 2002; Suzuki et al., 2008). Training consisted of placing the mice in the chamber and delivering an electrical footshock (2 s duration; $0.2 \mathrm{~mA}$ for Figs. $1 D, 2$ B, 3; $0.4 \mathrm{~mA}$ for Fig. $6 B$ ) $148 \mathrm{~s}$ later. Mice were returned to the home cage $30 \mathrm{~s}$ after the final footshock. Memory was assessed 2 or $24 \mathrm{~h}$ later by calculating the percentage of time spent freezing when replaced in the training context. Freezing behavior (defined as the complete lack of movement, except for respiration) was measured automatically as described previously (Anagnostaras et al., 2000) (OHARA Pharmaceutical).

Passive avoidance test. The step-through passive avoidance apparatus (OHARA Pharmaceutical) consisted of a box with separate light $(15.5 \times$ $12.5 \times 11.5 \mathrm{~cm})$ and dark $(15.5 \times 12.5 \times 11.5 \mathrm{~cm})$ compartments. The light compartment was illuminated by fluorescent light ( 2500 lux). During training sessions, each mouse was allowed to habituate to the light compartment for $30 \mathrm{~s}$, and the guillotine door was raised to allow access to the dark compartment. Latency to enter the dark compartment was considered as a measure of acquisition. As soon as the mice had entered the dark compartment, the guillotine door was closed. After $5 \mathrm{~s}$, a footshock $(0.2 \mathrm{~mA})$ was delivered for a total period of $2 \mathrm{~s}$. Memory was assessed $24 \mathrm{~h}$ or 3 weeks later as the crossover latency for the mice to enter into the dark compartment when replaced in the light compartment, as in training. If after $600 \mathrm{~s}$ mice did not enter the shock chamber, the test ended.

Social recognition test. The social recognition test was performed as described previously (Kogan et al., 2000). Mice were placed into individual plastic cages in an experimental room under dim light. The cages were identical with those in which mice were normally housed (plastic; $30 \mathrm{~cm}$ long by $17 \mathrm{~cm}$ wide by $12 \mathrm{~cm}$ high). After a period of $60 \mathrm{~min}$, a juvenile mouse was placed into a cage with a subject for a first interaction trial lasting 1.5 min (see Fig. $2 \mathrm{~A}$, analyses of transgenic CaMKIV line 1 mice) or $3 \mathrm{~min}$ (see Fig. $6 \mathrm{C}$ ). The duration of social investigation behavior exhibited by the juvenile, adult, or aged mouse was determined with a hand-held stopwatch. Social investigation was measured as described previously (Thor and Holloway, 1982). Memory was reassessed 2 or $24 \mathrm{~h}$ later by recording the length of investigation time exhibited by the subject to the same juvenile. To evaluate the differences of ability to form social memory between groups of mice, we calculated a recognition index, the ratio of the duration of the second and first investigation times.

Conditioned taste aversion test. After moving to individual cages, mice were given access to water from two bottles for $60 \mathrm{~min}$, and then returned to their home cages. On day 2, the mice were given access to water for 45 $\min$. On days 3 and 4, water access was limited to $30 \mathrm{~min}$. On day 5 (the day of conditioning), mice were given access for $15 \mathrm{~min}$ to two bottles with a $0.1 \%$ saccharin solution. Forty minutes later, mice were injected 
(2\% of body weight) with saline or $0.1 \mathrm{M} \mathrm{LiCl}$, and then returned to their cages. To prevent dehydration, mice were given $15 \mathrm{~min}$ for access to water $2 \mathrm{~h}$ after injection. On day 6 (the test day), mice were presented with the saccharin solution and water in separate bottles (bottle positions counterbalanced across cages). To determine consumption, bottles were weighed before and after testing. Aversion index was calculated as follows: [saccharin solution consumed/(saccharin solution consumed + water consumed) $\times 100]$.

Brain slice electrophysiology. Coronal brain slices $(300 \mu \mathrm{m})$ containing the hippocampus from 6- to 8-week-old wild-type and CaMKIV mice were prepared using standard methods (Zhao et al., 2005). Slices were transferred to a submerged recovery chamber with oxygenated $\left(95 \% \mathrm{O}_{2}\right.$ and 5\% $\mathrm{CO}_{2}$ ) ACSF containing the following (in mM): $124 \mathrm{NaCl}, 2.5 \mathrm{KCl}$, $2 \mathrm{CaCl}_{2}, 2 \mathrm{MgSO}_{4}, 25 \mathrm{NaHCO}_{3}, 1 \mathrm{NaH}_{2} \mathrm{PO}_{4}, 10$ glucose at room temperature for at least $1 \mathrm{~h}$. Whole-cell patch-clamp recordings were performed under visual guidance using an Olympus microscope fitted with infrared differential interference contrast optics (Olympus BX51WI). EPSCs were recorded from CA1 pyramidal neurons with an Axon 200B amplifier (Molecular Devices) and stimulations were delivered by a bipolar tungsten stimulating electrode placed in the striatum radium. EPSCs were induced by repetitive stimulations at $0.02 \mathrm{~Hz}$ and neurons were voltage clamped at $-70 \mathrm{mV}$. The recording pipettes $(3-5 \mathrm{M} \Omega$ ) were filled with solution containing the following (in $\mathrm{mm}$ ): $145 \mathrm{~K}$-gluconate, 5 $\mathrm{NaCl}, 1 \mathrm{MgCl}_{2}, 0.2$ EGTA, 10 HEPES, $2 \mathrm{Mg}$-ATP, and $0.1 \mathrm{Na}_{3}$-GTP, adjusted to $\mathrm{pH} 7.2$ with $\mathrm{KOH}$. The induction protocol (referred to as spike-timing protocol) for LTP involved paired three presynaptic stimuli, which caused three EPSPs (10 ms ahead) with three postsynaptic action potentials at $30 \mathrm{~Hz}$, paired 15 times every $5 \mathrm{~s}$. The NMDA receptor-mediated component of EPSCs was pharmacologically isolated in ACSF containing the following: CNQX $(20 \mu \mathrm{M})$ and picrotoxin $(100$ $\mu \mathrm{M})$. The patch electrodes for measuring NMDA receptor-mediated EPSCs contained the following (in mM): $102 \mathrm{CsMeSO}_{3}, 5$ TEA (tetraethylammonium) chloride, $3.7 \mathrm{NaCl}, 11$ BAPTA, 0.2 EGTA, 20 HEPES, 2 MgATP, $0.3 \mathrm{NaGTP}$, and 5 QX-314 (lidocaine $\mathrm{N}$-ethyl bromide) chloride, adjusted to $\mathrm{pH} 7.2$ with $\mathrm{CsOH}$. Neurons were voltage clamped at $-30 \mathrm{mV}$ and NMDA receptor-mediated EPSCs were evoked at $0.05 \mathrm{~Hz}$. Picrotoxin $(100 \mu \mathrm{M})$ was always present to block $\mathrm{GABA}_{\mathrm{A}}$ receptormediated inhibitory currents and monitored throughout the synaptic currents. Access resistance was 15-30 M $\Omega$ and was monitored throughout the experiment. Data were discarded if access resistance changed $>15 \%$ during an experiment.

Data analysis. Data were analyzed by ANOVA. A two-way ANOVA and Newman-Keuls post hoc comparisons were used to analyze the effects of genotypes and age of mice. A paired $t$ test was used to analyze differences of social investigation times within each group between first and second exposures to the same juvenile. All values in the text and figure legends represent mean \pm SEM.

\section{Results}

\section{Generation of CaMKIV overexpression mice}

To generate transgenic mice overexpressing CaMKIV in the forebrain, we constructed a transgene that contained an $\alpha$ CaMKII promoter, a hybrid intron in the $5^{\prime}$-untranslated leader, the coding region of CaMKIV fused with the Flag tag sequence at the $\mathrm{N}$ terminus, and a polyadenylation signal (Fig. $1 A$ ). The $\alpha$ CaMKII promoter has been known to exhibit strong activity in regions of the forebrain including the hippocampus, cortex, and striatum (Mayford et al., 1996; Kida et al., 2002). In the present study, we generated three lines of transgenic mice and performed expression analyses. Northern blot analysis, using a specific probe for the transgene mRNA, showed that a transgene transcript was expressed in all three lines and that transgenic lines 1 and 2 highly express transgene mRNA (Fig. $1 B$ ). Western blot analysis, performed using anti-FLAG antibody, detected the epitope tag of the transgenic CaMKIV protein in the hippocampus of CaMKIV mice (Fig. 1C), confirming the results of Northern blot analyses. Consistent with this, in situ hybridization analyses revealed higher levels of transgene mRNA in the CA1, CA3, and dentate gyrus of the hippocampal and cortical regions in transgenic line 2 mice (Fig. 1D). However, we observed only low signal density of transgene mRNA in the amygdala (Fig. 1D). With the exception of behavioral studies, we selected transgenic line 2 for additional characterization experiments because this strain exhibits the highest levels of transgene expression among the three transgenic lines (Fig. 1D).

To examine the effect of CaMKIV overexpression in the forebrain, we analyzed the level of phosphorylated CREB at serine 133 in the CA1 region of the hippocampus after learning. The behavioral task that we chose was contextual fear conditioning, a form of associative memory between context [conditioned stimulus (CS)] and aversive stimulus [unconditioned stimulus (US)]. Mice were trained with footshock (0.2 mA; CS-US) or no footshock (CS only), and the level of pCREB was assessed $30 \mathrm{~min}$ after conditioning by Western blot analysis. Two-way ANOVA identified significant effects related to genotype and conditioning (Fig. 1E) (genotype, $F_{(1,16)}=12.848, p<0.05$; conditioning, $\left.F_{(1,16)}=20.735, p<0.05\right)$. Newman-Keuls post hoc analyses showed that pCREB level was significantly higher in conditioned WT and CaMKIV mice, compared with unconditioned WT and CaMKIV mice, respectively $(p<0.05)$, indicating that in accordance with previous findings (Impey et al., 1998), contextual fear learning was associated with increased levels of pCREB in the CA1 region of the hippocampus. More importantly, CaMKIV mice exhibited significantly higher pCREB levels after contextual fear conditioning compared with WT mice $(p<0.05)$. This higher, learning-induced, level of pCREB in transgenic mice is thought to reflect the increased basal pCREB level (see below).

In addition, the basal level of phosphorylated CREB in the hippocampus (without any treatment) was significantly greater in unconditioned CaMKIV mice compared with unconditioned WT littermates (supplemental Fig. 1, available at www. jneurosci.org as supplemental material). This result suggests that the overexpression of CaMKIV results in increased activity, thereby resulting in increased levels of phosphorylated CREB. Consistent with this, Northern blot analysis revealed that 14-3-3 eta and c-fos expression, thought to be elevated by the activation of CREB (Sheng et al., 1991; Kida et al., 2002), were increased in the hippocampus and cortex of CaMKIV mice, compared with WT littermates (supplemental Fig. 1, available at www. jneurosci.org as supplemental material).

\section{Effect of CaMKIV overexpression on memory formation}

Overexpression of CaMKIV in the forebrain might affect the ability to form hippocampus-dependent memory. To test this, we performed aversive and nonaversive hippocampus-dependent memory tasks using transgenic mice and the WT littermates. In these memory tests, mice were trained using weaker protocols that were expected to enable us to more likely observe the enhanced ability for memory formation in CaMKIV mice.

We first performed the social recognition test to examine the ability to form nonaversive social memory (Fig. 2A). This task measures the difference in time taken to investigate a juvenile mouse when compared between first and second exposure for 1.5 min. Second exposure was performed 2 or $24 \mathrm{~h}$ after first exposure. Two-way ANOVA comparing recognition index, the ratio of the second investigation time relative to the first investigation time, identified significant effects related to time point (STM or LTM), genotype, and the interaction between time point and genotype (time point, $F_{(1,37)}=6.089, p<0.05$; genotype, $F_{(1,37)}$ $=9.041, p<0.05$; time point vs genotype, $F_{(1,37)}=5.343, p<$ 
A

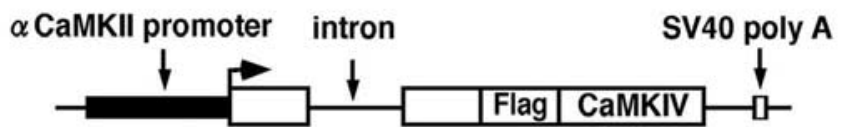

B
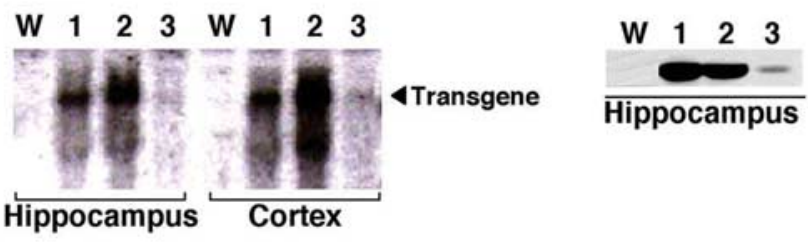

D

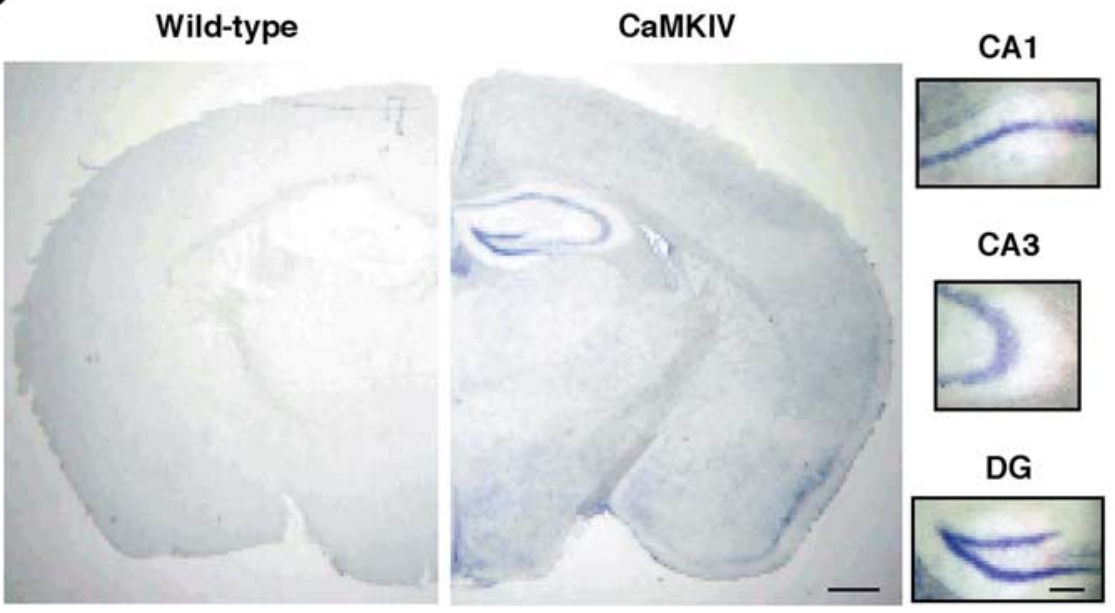

E
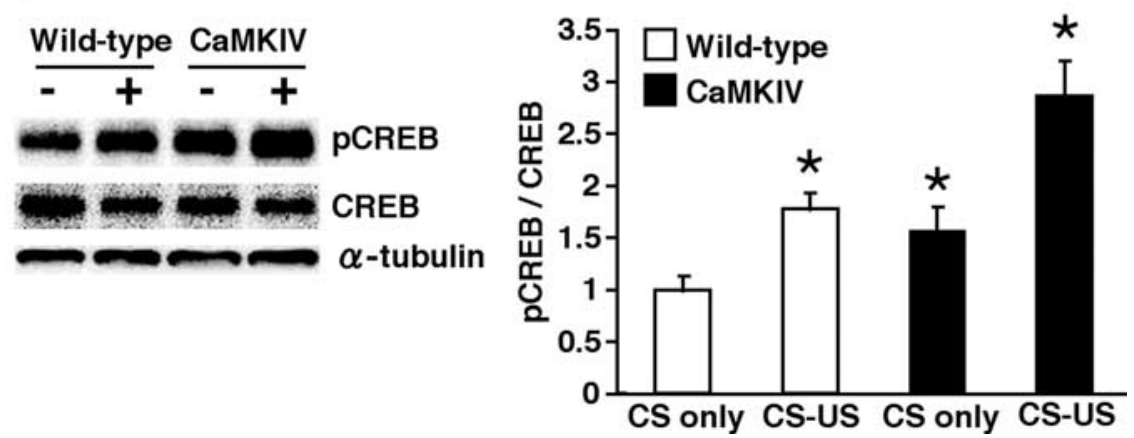

Figure 1. Generation and expression analyses of CaMKIV overexpression mice. $\boldsymbol{A}$, Schematic representation of the CaMKIV transgenic construct. $\boldsymbol{B}$, Northern blot analysis of the transgene in the hippocampus and cortex of WT mice (W) and CaMKIV transgenic lines 1, 2, and 3. The SV40 poly(A) probe detected transgenic mRNA of $2.5 \mathrm{~kb}$. C, Western blot analysis of transgenic CaMKIV expression in the hippocampus and cortex of WT mice and transgenic lines 1,2, and 3. The anti-FLAG antibody detected a $60 \mathrm{kDa}$ protein corresponding to CaMKIV.D, In situ hybridization analyses of transgene mRNA expression in the CaMKIV (line 2) and WT mice. The SV40 poly(A) probe detected transgene mRNA in the forebrain of CaMKIV transgenic line 2 mice. Scale bar, $500 \mu \mathrm{m}$. Higher magnification of CA1, CA3, and dentate gyrus (DG) areas showed abundant expression of transgene mRNA. Scale bar, $100 \mu \mathrm{m}$. $\boldsymbol{E}$, Western blot analysis of ratio of the level of phosphorylated CREB and CREB in the CA1 region of hippocampus of WT and CaMKIV mice after fear conditioning (left). Levels of phosphorylated CREB were normalized according to the CREB signal. Quantification of ratio of phosphorylated (REB and total CREB in WT and CaMKIV mice after conditioning (right; CS-only WT, $n=6$; CS-USWT, $n=5$; CS-only CaMKIV, $n=5$; CS-US CaMKIV, $n=4$ ). ${ }^{*} p<0.05$ compared with CS-only WT mice. Error bars indicate SEM.

0.05). CaMKIV mice showed comparable short-term (ST), but enhanced long-term (LT), social recognition memory formation compared with WT littermates (STM, $p>0.05$; LTM, $p<0.05$ ). Comparison of first and second investigation time confirmed

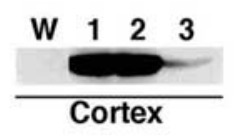

these observations (supplemental Fig. 2, available at www.jneurosci.org as supplemental material). Two hours after the first exposure, both WT and CaMKIV mice showed significant reduction in investigation time $\left(\mathrm{WT}, t_{(9)}=5.304, p<0.05\right.$; CaMKIV, $\left.t_{(8)}=6.31, p<0.05\right)$, indicating that both groups formed ST social memory. In contrast, $24 \mathrm{~h}$ after the first exposure, CaMKIV but not WT mice showed significant reduction in investigation time $\left(\mathrm{WT}, t_{(11)}=1.19, p>0.05\right.$; CaMKIV, $t_{(9)}$ $=8.907, p<0.05)$. These results indicate that, in these experimental conditions, CaMKIV mice formed LT social memory, whereas WT mice did not.

We next performed the contextual fear conditioning task to examine the ability to form aversive memory (Fig. $2 B$ ). Mice were trained with a single footshock $(0.2$ $\mathrm{mA}$ ) and behavioral freezing either 2 or $24 \mathrm{~h}$ after training was assessed. Two-way ANOVA identified significant effects related to time point, genotype, and the interaction between time point and genotype (time point, $F_{(1,34)}=15.642, p<0.05$; genotype, $F_{(1,34)}=4.181, p<0.05$; time point vs genotype, $\left.F_{(1,34)}=4.241, p<0.05\right)$. As shown in Figure $2 B$, there was no significant difference in contextual freezing across groups during training or $2 \mathrm{~h}$ later. In contrast, $24 \mathrm{~h}$ later, CaMKIV mice were shown to freeze significantly more than WT mice $(p<0.05)$. Thus, the overexpression of CaMKIV enhanced LTM formation of contextual fear without affecting STM.

In addition, we also investigated whether CaMKIV overexpression in the forebrain affects the ability to form hippocampus-independent memory. To do this, we performed the conditioned taste aversion test that has previously been shown to be amygdala- and insular cortex-dependent (Berman and Dudai, 2001; Josselyn et al., 2004) (Fig. 2C). The conditioned taste aversion task examines the ability to form associative memory between saccharin as the CS and a malaise-inducing agent (intraperitoneal injection of $\mathrm{LiCl}$ ) as the US. Mice were injected with saline or $0.1 \mathrm{M} \mathrm{LiCl}$ on the day of conditioning. Both LiCl-injected WT and CaMKIV mice showed a significantly lower aversion index compared with saline-injected controls, respectively, $24 \mathrm{~h}$ after the conditioning (saline WT, $n=7$; LiCl WT, $n=9$; $F_{(1,14)}=$ 14.887, $p<0.05$; saline CaMKIV, $n=$ 10; LiCl CaMKIV, $n=9 ; F_{(1,17)}=$ $31.263, p<0.05)$. In contrast to the results shown in Figure 2, $A$ and $B$, there was no significant difference between CaMKIV and WT mice in the index of conditioned taste aversion when tested $24 \mathrm{~h}$ after training (Fig. 2C). 
A

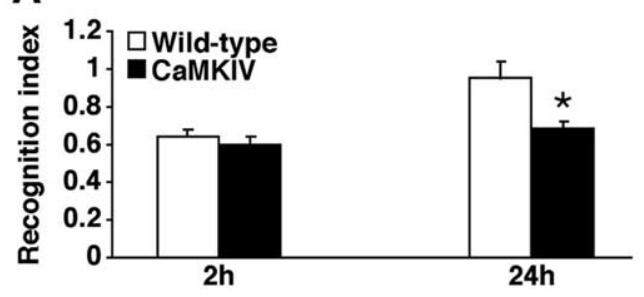

B
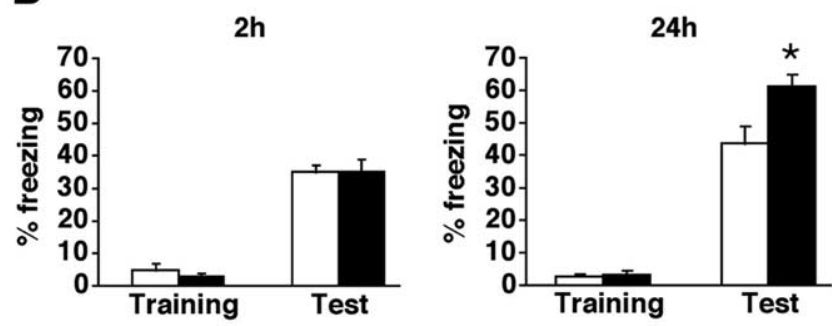

C

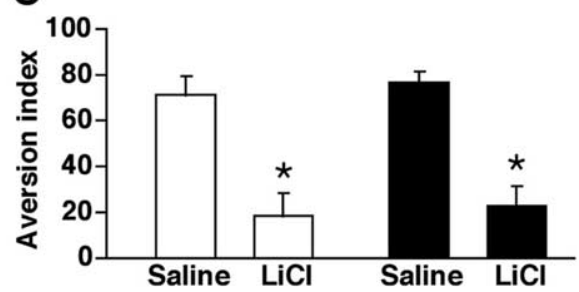

Figure 2. Enhanced memory consolidation in transgenic CaMKIV line 2 mice. $A$, Comparison of recognition index at $2 \mathrm{~h}(\mathrm{WT}, n=10$; CaMKIV,$n=9$ ) or $24 \mathrm{~h}(\mathrm{WT}, n=12$; CaMKIV, $n=10$ ) after training for 1.5 min. ${ }^{*} p<0.05$ compared with WT mice. $B$, Freezing responses during training and at $2 \mathrm{~h}$ (WT, $n=8$; CaMKIV, $n=8$ ) or $24 \mathrm{~h}$ (WT, $n=12$; CaMKIV, $n=10$ ) after training. ${ }^{*} p<0.05$ compared with WT mice. Error bars indicate SEM. C, Both LiCl-injected WT and CaMKIV mice showed a significantly lower aversion index compared with saline-injected controls, respectively, $24 \mathrm{~h}$ after the conditioning (saline WT, $n=7$; LiCl WT, $n=9$; saline CaMKIV, $n=10$; LiCl CaMKIV, $n=9$ ). ${ }^{*} p<0.05$ compared with saline injected in WT and CaMKIV mice, respectively. Error bars indicate SEM.

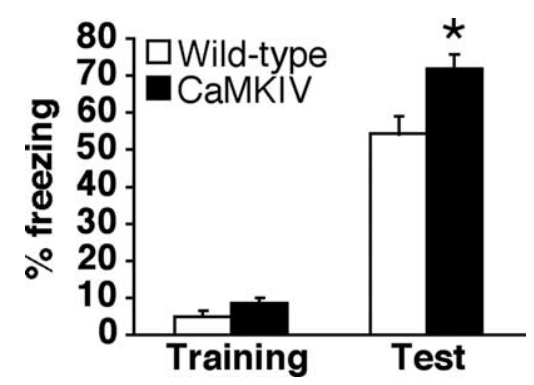

Figure 3. Enhanced memory formation in transgenic CaMKIV line 1 mice. Freezing responses during training and at $24 \mathrm{~h}$ after training (WT, $n=10$; CaMKIV, $n=9$ ). ${ }^{*} p<0.05$ compared with WT mice. Error bars indicate SEM.

It is important to note that we observed similar enhancement of LTM formation in CaMKIV transgenic line 1 mice during social recognition and contextual fear memory tasks (Fig. 3). In social recognition paradigms, one-way ANOVA was used to investigate recognition index and identified a significant effect related to genotype [WT $(n=6), 0.98 \pm 0.09$; CaMKIV $(n=7)$, $\left.0.70 \pm 0.07 ; F_{(1,11)}=5.584 ; p<0.05\right]$. Consistent with this is that $24 \mathrm{~h}$ after the first exposure, CaMKIV mice, but not WT mice, showed significant reduction in investigation time (supplemental Fig. 3, available at www.jneurosci.org as supplemental material) $\left(\mathrm{WT}, t_{(1,5)}=0.661, p>0.05\right.$; CaMKIV $\left.t_{(1,6)}=3.65, p<0.05\right)$.
These results indicate that CaMKIV mice formed LT social memory, but WT mice did not. In contextual fear conditioning paradigms (Fig. 3), one-way ANOVA comparing contextual freezing tested $24 \mathrm{~h}$ after training identified a significant effect related to genotype $\left(F_{(1,17)}=7.364 ; p<0.05\right)$. Transgenic line 1 mice were shown to freeze significantly more than WT mice $(p<0.05)$. These observations suggest that the enhancement of memory formation by forebrain-specific overexpression of CaMKIV observed in transgenic line 2 mice was not attributable to positional effects of transgene integration sites.

These results presented in Figures 2 and 3 indicate that the upregulation of CaMKIV activity in forebrain improves ability for memory consolidation. Together with the results of Figure 1, we suggest that the expression level of CaMKIV positively correlates with the ability for memory consolidation.

\section{Effects of CaMKIV overexpression on basal synaptic transmission and LTP}

LTP in the hippocampus is thought to recapitulate some aspects of the mechanisms underlying hippocampus-dependent memory formation (Bliss and Collingridge, 1993; Nguyen et al., 1994; Frey and Morris 1998; Martin et al., 2000; Malenka, 2003; Lynch, 2004). We therefore want to assess whether LTP is altered in CaMKIV mice. We first characterized the basal synaptic transmission in hippocampal CA1 pyramidal neurons in the transgenic mice. AMPA or NMDA receptor-mediated EPSCs in WT and CaMKIV mice were compared. We found that the inputoutput relationship of AMPA receptor EPSCs in CaMKIV mice was similar to those in WT mice at a variety of stimulus intensities (Fig. 4A). Similarly, there was no difference in NMDA receptor EPSCs between the two groups (Fig. $4 B)(p>0.05)$. Second, we studied the paired-pulse facilitation (PPF) of EPSCs, a simple form of presynaptic plasticity (Creager et al., 1980). We found no differences in PPF between WT and CaMKIV mice, at any of the intervals (Fig. 4C) ( $p>0.05)$. Finally, we studied LTP in hippocampal CA1 neurons in both WT and CaMKIV mice. The spike timing protocol was used to induce synaptic potentiation in WT mice (Fig. 4D) (167.0 $\pm 9.8 \%$ of baseline response; $p<0.05$ compared with baseline response before induction). Using the same protocol, we found that LTP was significantly increased in CaMKIV mice compared with WT mice (Fig. 4D) (244.5 土 $10.2 \%$ of baseline response; $p<0.05$ compared with LTP in WT mice). Collectively, these data suggest that LTP, but not basal synaptic transmission, is significantly enhanced in CaMKIV mice.

\section{Relationship between CaMKIV expression and memory performance in aged mice}

A recent study suggested that the expression of CaMKIV declines with age in the human brain ( $\mathrm{Lu}$ et al., 2004). It is possible that this age-related decrease in CaMKIV expression might also be observed in mice and affects the ability for memory formation. Therefore, we examined the relationship between the level of CaMKIV expression and memory performance in adult and aged WT mice. To do this, we first examined the effects of age on contextual fear memory using adult (3-6 months old) and aged ( $>18$ months old) mice (Fig. 5). Mice were trained under our normal training conditions ( $0.4 \mathrm{~mA}$ footshock) (Suzuki et al., 2008) and were then assessed $24 \mathrm{~h}$ later by freezing response. Aged WT mice exhibited significantly less freezing compared with adult WT mice [adult $(n=10), 51.6 \pm 2.58 \%$; aged $(n=$ $\left.11), 33.6 \pm 3.49 \% ; F_{(1,19)}=16.66, p<0.05\right]$, indicating an agerelated impairment of the ability to form contextual fear mem- 
A

\section{AMPA EPSCs}
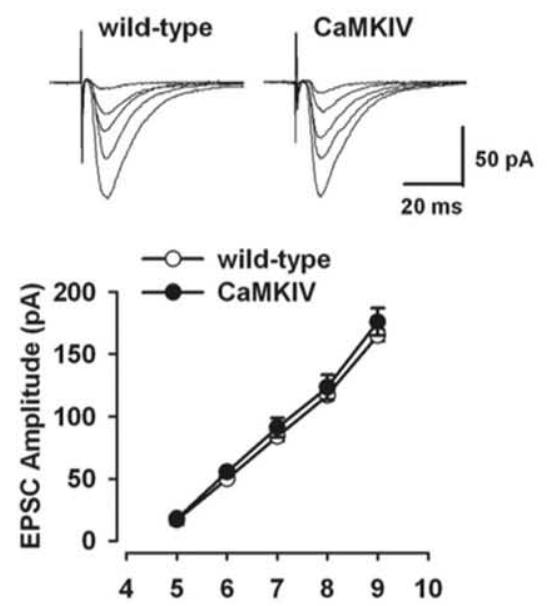

Stimulation Intensity (V)

C
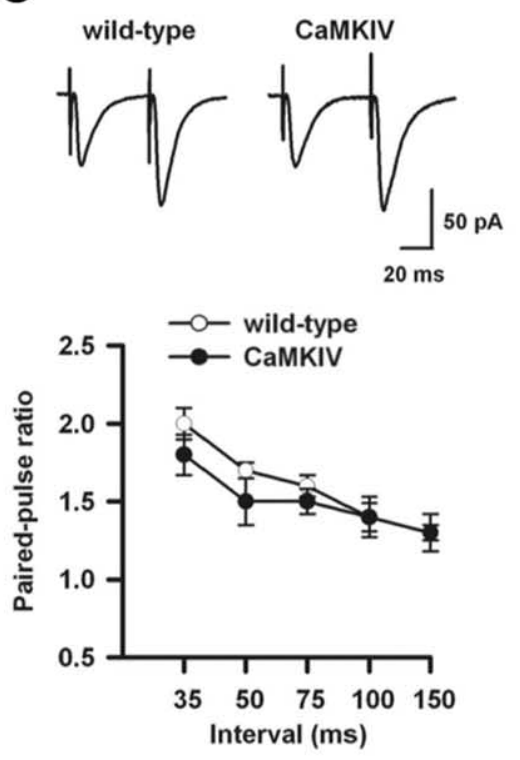

B

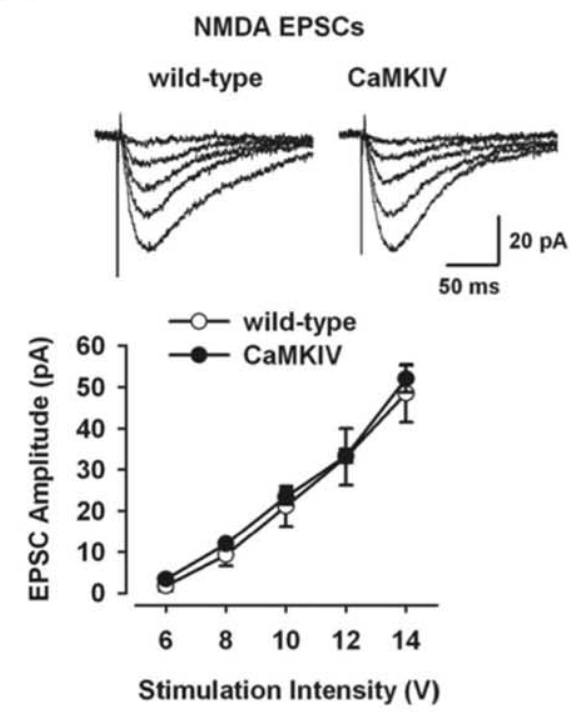

D

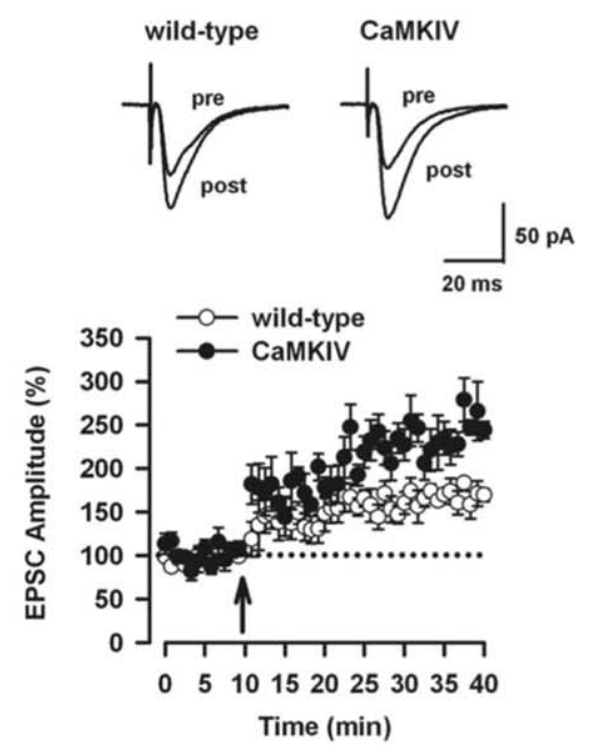

Figure 4. Enhanced LTP in the hippocampal CA1 neurons of CaMKIV mice. $A$, Input- output relationship for AMPA receptormediated EPSCS (WT, $n=5$; CaMKIV, $n=6$ ). The insets show sample traces of AMPA EPSCs at various stimulation intensities. $\boldsymbol{B}$, Input- output relationship for NMDA receptor-mediated EPSCs (WT, $n=6$; CaMKIV, $n=6$ ). The insets show sample traces of NMDA EPSCS at various stimulation intensities. C, Paired-pulse facilitation (WT, $n=7$; CaMKIV, $n=7$ ). The insets show sample traces obtained at $50 \mathrm{~ms}$ intervals. $\boldsymbol{D}$, LTP induced by the spike-timing protocol in CA1 neurons (WT, $n=8$; CaMKIV, $n=7$ ). The insets show the average of six EPSCs at baseline response and $30 \mathrm{~min}$ after the LTP induction, respectively. Error bars indicate SEM.

ory. To examine the effects of age on CaMKIV expression in the hippocampus, we next performed Western blot analysis of proteins from the hippocampus of adult and aged WT mice used in contextual fear conditioning. The results of Western blotting using an anti-CaMKIV antibody indicated that aged WT mice expressed hippocampal CaMKIV at lower levels compared with adult WT mice [fold change of CaMKIV expression level; adult $(n=10), 1 \pm 0.08 ;$ aged $(n=11), 0.54 \pm 0.11 ; F_{(1,19)}=11.169 ;$ $p<0.05]$. In parallel with the case of the human brain, CaMKIV expression in the mouse hippocampus declines with aging.

To further clarify the implication of CaMKIV expression levels with the ability to form memory in aged mice, we compared
CaMKIV expression levels and memory performance associated with contextual fear conditioning in adult and aged WT mice. Figure 5 shows the relationship between the levels of CaMKIV expression in the hippocampus and freezing response tested $24 \mathrm{~h}$ after contextual fear conditioning in adult and aged WT mice. There was no significant correlation between CaMKIV levels and freezing scores in adult WT mice $(r=0.524 ; p>0.05)$. In contrast, aged WT mice revealed a significant correlation between hippocampal CaMKIV level and freezing scores $(r=$ $0.785 ; p<0.05)$. These results indicate a positive correlation between CaMKIV level and memory performance in aged but not adult WT mice, suggesting that age-related decline of CaMKIV expression levels with aging is associated with agerelated memory deficits.

\section{Effect of CaMKIV overexpression on aged-related memory deficits}

CaMKIV overexpression in the forebrain might affect age-related memory deficits. Before testing this, we compared CaMKIV expression level in the hippocampus of adult and aged CaMKIV and WT mice (Fig. 6A). Two-way ANOVA identified significant effects related to genotype and age (genotype, $F_{(1,22)}=18.243, p<0.05$; age, $\left.F_{(1,22)}=5.302, p<0.05\right)$. Post hoc analyses showed that adult CaMKIV mice express CaMKIV at higher levels than any of the other three groups $(p<0.05)$. Consistent with results above, CaMKIV expression in the mouse hippocampus declines with aging in WT mice. However, aged CaMKIV mice exhibited higher and comparable expression levels of CaMKIV compared with aged and adult WT mice, respectively. These results indicate that CaMKIV expression declines with aging and that this downregulation of CaMKIV can be rescued in transgenic mice by overexpressing CaMKIV.

We next performed hippocampusdependent memory tasks (contextual fear conditioning, passive avoidance, and social recognition) using adult and aged CaMKIV and WT mice. In these behavioral tests, mice were trained using normal training protocols (Kogan et al., 2000; Callaerts-Vegh et al., 2006; Suzuki et al., 2008).

In contextual fear conditioning paradigms, mice were trained with footshock $(0.4 \mathrm{~mA})$, and 2 or $24 \mathrm{~h}$ later, freezing response was tested. As shown in Figure $6 B$, there were no significant differences in contextual freezing observed across groups during training and $2 \mathrm{~h}$ later. In contrast, $24 \mathrm{~h}$ after training, two-way ANOVA revealed significant effects of genotype and age of mice (genotype, $F_{(1,45)}=11.317, p<0.05$; age, $F_{(1,45)}=17.341, p<$ $0.05)$. Our data demonstrated that aged WT mice froze significantly less than adult WT mice and as such is in line with 
previous observations showing that aged WT mice exhibit impaired memory formation (Bach et al., 1999). However, aged CaMKIV mice exhibited significantly more and comparable freezing compared with aged and adult WT mice, respectively, suggesting that the overexpression of CaMKIV rescues age-related memory deficits.

In social recognition paradigms, mice were exposed to a juvenile mouse for 3 min. In these experimental conditions, all of the groups formed long-term social recognition memory (supplemental Fig. 4, available at www.jneurosci.org as supplemental material) (adult wild type, $t_{(15)}=$ 13.84; aged wild type, $t_{(16)}=2.151$; adult CaMKIV, $t_{(11)}=8.554$; aged CaMKIV,
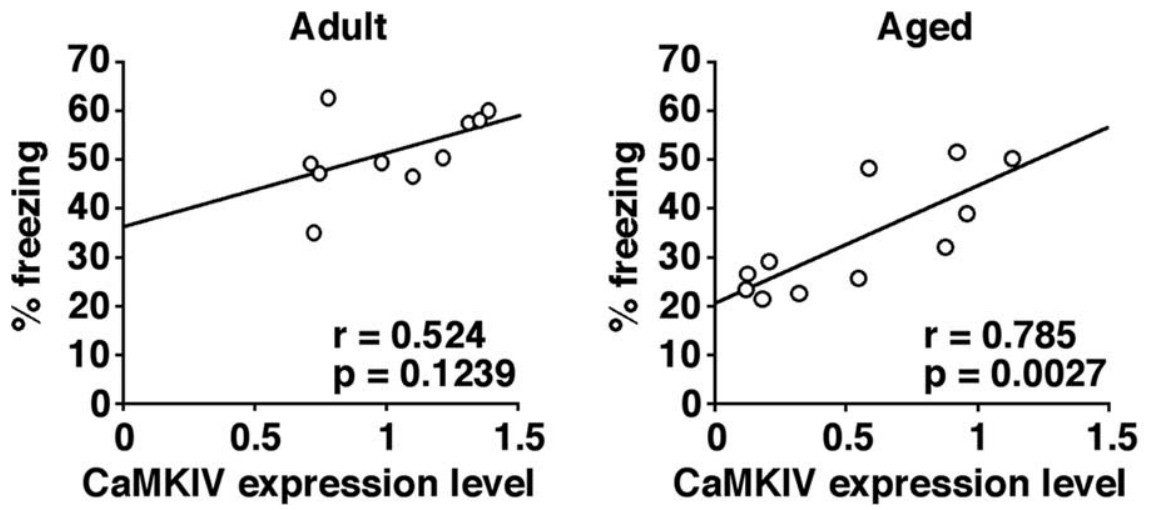

Figure 5. Relationship between CaMKIV expression level and memory performance in WT mice. A comparison between CaMKIV expression in the hippocampus and freezing response tested $24 \mathrm{~h}$ after training of contextual fear conditioning in adult is shown (left; $n=10$ ) or aged (right; $n=11$ ) mice. $\left.t_{(18)}=4.636, p<0.05\right)$. However, as shown in Figure $6 C$, twoway ANOVA of recognition index revealed significant effects of genotype and the age of mice (genotype, $F_{(1,60)}=8.218, p<0.05$; age, $\left.F_{(1,60)}=24.464, p<0.05\right)$. Aged WT mice exhibited a significantly higher recognition index than the other groups including aged CaMKIV mice, indicating that the degree of LTM formation is impaired with aging and that the overexpression of CaMKIV prevents this impairment.

To further examine the effects of CaMKIV overexpression on LTM, we next performed the passive avoidance task. This task examines the ability to form memory to avoid a context previously associated with an aversive stimulus. During training, mice received a single electrical footshock $(0.2 \mathrm{~mA})$ immediately after their entry into a dark box. Twenty-four hours, or 3 weeks later, mice were assessed for crossover latency until their entry into the dark box from the light box. As shown in Figure $6 D$, there were no significant differences in crossover latency observed across groups during training or $24 \mathrm{~h}$ later in these experimental conditions. In contrast, 3 weeks after training, two-way ANOVA revealed significant interaction between genotype and age (genotype, $F_{(1,39)}=4.003, p>0.05$; age, $F_{(1,39)}=3.662, p>0.05$; genotype vs age, $\left.F_{(1,39)}=4.583, p<0.05\right)$. Aged WT mice exhibited significantly lower crossover latency compared with the other three groups including aged CaMKIV mice, whereas other groups showed comparable crossover latency. These results indicated that aging impairs long-lasting long-term avoidance memory and that the overexpression of CaMKIV can prevent this age-related impairment to the establishment of remote avoidance memory. However, it is possible that there were no differences in crossover latency when tested $24 \mathrm{~h}$ after training as a result of a ceiling effect in this experimental condition. Nevertheless, the significant difference observed 3 weeks after training between aged WT and CaMKIV suggested the impact of CaMKIV on the formation of remote memory in aged mice.

\section{Discussion}

Memory consolidation is known to be a gene expressiondependent process that generates LTM (Flexner et al., 1965; Davis and Squire, 1984; Abel et al., 1997; Silva et al., 1998; Martin et al., 2000; McGaugh, 2000). CaMKIV is thought to regulate the gene expression required for memory consolidation via the activation of CREB-CBP-mediated transcription. Loss of CaMKIV function by genetic deletion has been shown to reduce levels of the phosphorylated form of CREB and impair the formation of LTM of contextual fear without affecting STM (Wei et al., 2002). Con- sistent with this, genetic inhibition of CREB or CBP disrupts LTM but not STM of contextual fear (Oike et al., 1999; Kida et al., 2002; Alarcón et al., 2004). In this study, we generated transgenic mice overexpressing CaMKIV in the forebrain and examined the effects of CaMKIV overexpression on the consolidation of aversive and nonaversive memories. Upregulation of CaMKIV led to increased learning-induced levels of phosphorylated CREB and improvements in LTM of contextual fear, passive avoidance, and social recognition, without affecting STM. However, we observed reductions in the level of CaMKIV expression in mouse hippocampus that were clearly associated with aging and, more importantly, positive correlation between CaMKIV expression level and memory performance in aged mice. Moreover, transgenic overexpression of CaMKIV was shown to prevent the reduction in CaMKIV and, furthermore, improved age-related disability in memory formation. Collectively, these observations suggest that the expression level of CaMKIV correlates positively with the ability to generate LTM and that CaMKIV acts as a positive molecular switch of LTM formation, especially memory consolidation via increased CREB activity.

In parallel with a previous report suggesting age-related decrease in CaMKIV expression in human frontal cortex ( $\mathrm{Lu}$ et al., 2004), we observed reduced CaMKIV expression in the mouse hippocampus with aging (that is associated with memory deficits). Correlation between CaMKIV expression level and memory performance in contextual fear conditioning suggests that this age-dependent decrease in CaMKIV expression is implicated with age-related memory deficits. Our present results showing that the overexpression of CaMKIV in the forebrain blocks the impairment of memory formation in aged mice supports this hypothesis, especially when considered collectively with previous findings showing that the viral expression of CREB attenuates memory deficits in aging rats (Mouravlev et al., 2006). The CaMKIV-CREB signaling pathway might therefore be a major target of drug development for the improvement of memory disorders including age-related memory deficits.

LTP in the hippocampus is thought to recapitulate some aspects of the mechanisms underlying hippocampus-dependent memory formation. In this study, we observed that the overexpression of CaMKIV enhanced LTP in CA1 neurons without affecting basal synaptic transmission. Conversely, previous studies have shown that the deletion of CaMKIV impairs induction and maintenance of LTP in CA1 neurons (Ho et al., 2000), whereas partial inhibition of CaMKIV by forebrain-specific transgenic expression of a dominant-negative CaMKIV mutant 
A
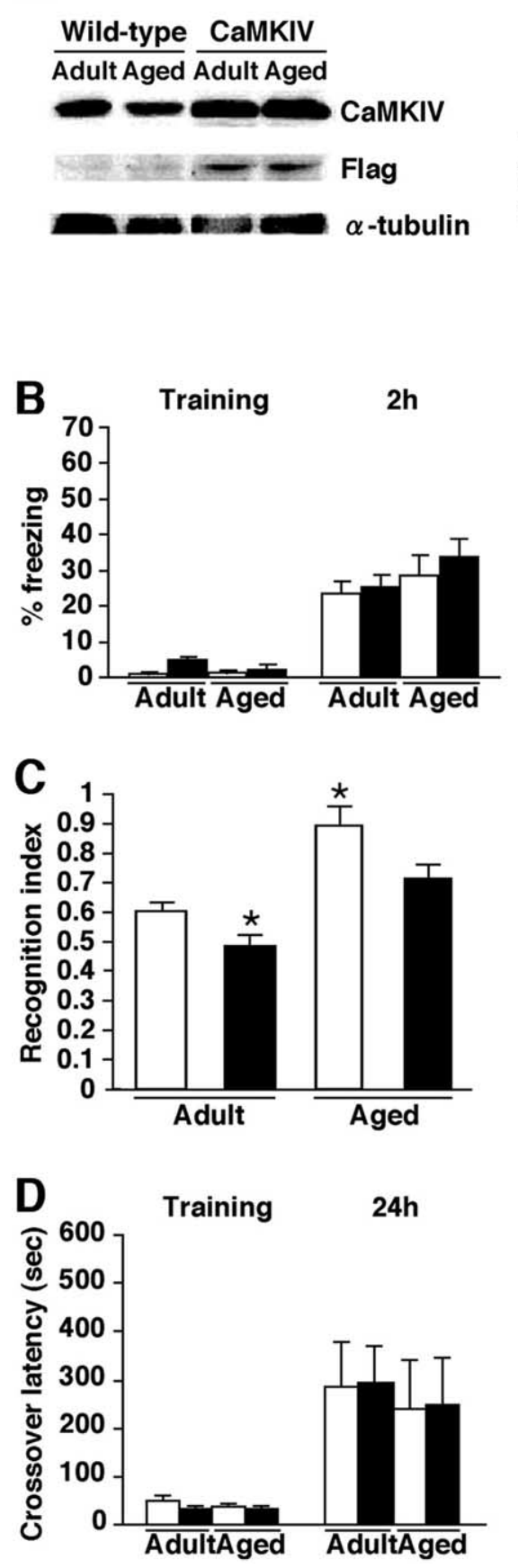
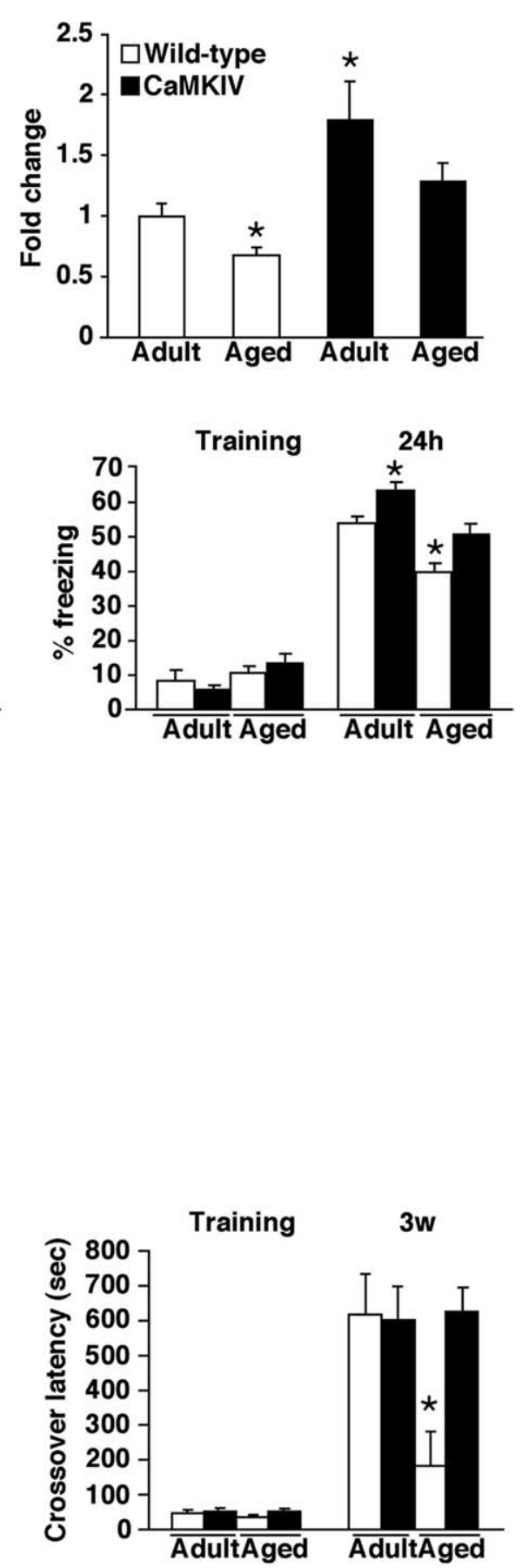

the possibility that enhanced synaptic plasticity in areas other than hippocampus CA1, such as the amygdala (Wei et al., 2002) or the anterior cingulate cortex ( $\mathrm{Wu}$ et al., 2008), also contributes to enhanced memory formation observed in CaMKIV mice. It is necessary to further examine the effect of CaMKIV expression on the synaptic plasticity of other such areas. Interestingly, a previous study has shown that the activation of CaMKIV by the viral expression of a dominant-active CaMKIV mutant not only enhances LTP but also modulates basal synaptic transmission by increasing both AMPA receptor- and NMDA receptor-mediated synaptic transmission (Marie et al., 2005). Although the effects of wild-type CaMKIV expression have not been examined in this viral system, levels of CaMKIV expression in excess of those produced by the transgenic mice used in our present study or the transgenic expression of a dominantactive CaMKIV mutant might be required to modulate basal synaptic transmission. In addition, it is important to note that there are no reports concerning the modulation of basal synaptic transmission in the CA1 hippocampal region associated with the deletion of the CaMKIV gene or the expression of dominant-negative CaMKIV.

It has been speculated that the storage and retrieval of recent memory depends on hippocampus function, whereas remote memory depends on cortical function or the cortical-hippocampus network (Kim and Fanselow, 1992; Eichenbaum et al., 1994; McClelland et al., 1995; Squire and Alvarez, 1995; Anagnostaras et al., 1999, 2001; Quevedo et al., 1999; LeDoux, 2000; McGaugh, 2000; Frankland et al., 2001). $\alpha$ CaMKII has been shown to play essential roles in initial learning and the establishment of the persistent memory of contextual fear (Silva et al., 1992). Mice homozygous for a null mutation of $\alpha$ CaMKII showed severe deficits in learning and memory (Silva et al., 1992), whereas $\alpha$ CaMKII heterozygous mice exhibited normal learning and recent memory $(1 \sim 3 \mathrm{~d})$ but failed to form persistent memory ( $\sim 3$ weeks) (Frankland et al., 2001). Thus, $\alpha$ CaMKII exhibits dosedependent effects on learning and memory; the lack of $\alpha$ CaMKII severely impaired initial learning, whereas reduced expression of $\alpha$ CaMKII impaired the formation of persistent memory without af-

Higure 6. Improvement of age-related memory deficits in CaMKIV mice. $\boldsymbol{A}$, Western blot analysis of hippocampal proteins extracted from adult and aged WT and CaMKIV mice. Anti-CaMKIV and anti-FLAG antibodies detected a $60 \mathrm{kDa}$ protein corresponding to CaMKIV. Quantification of CaMKIV expression from WT mice and CaMKIV mice (adult WT, $n=8$; adult CaMKIV, $n=$ 5; aged WT, $n=8$; aged CaMKIV, $n=5$ ). Levels of CaMKIV protein were normalized according to the $\alpha$-tubulin signal. ${ }^{*} p<0.05$ compared with adult WT mice. Error bars indicate SEM. B, Freezing responses during training and at $2 \mathrm{~h}$ (adult WT, $n=17$; adult CaMKIV, $n=10$; aged WT, $n=24$; aged CaMKIV, $n=7$ ) or $24 \mathrm{~h}$ (adult WT, $n=10$; adult CaMKIV, $n=10$; aged WT, $n=14$; aged CaMKIV, $n=16$ ) after training. ${ }^{*} p<0.05$ compared with adult WT mice. C, Comparison of recognition index at $24 \mathrm{~h}$ after training for $3 \min$ (adult WT, $n=10$; adult CaMKIV, $n=10$; aged WT, $n=17$; aged CaMKIV, $n=19$ ). ${ }^{*} p<0.05$ compared with adult WT mice. $\boldsymbol{D}$, Crossover latency during training and at $24 \mathrm{~h}$ (adult WT, $n=8$; adult CaMKIV, $n=14$; aged WT, $n=8$; aged CaMKIV, $n=$ 6) or 3 weeks (adult WT, $n=9$; adult CaMKIV, $n=9$; aged WT, $n=16$; aged CaMKIV, $n=10$ ) after training. ${ }^{*} p<0.05$ compared with crossover latency of other groups after 3 weeks. Error bars indicate SEM.

only maintains LTP (Kang et al., 2001). Thus, similar dosedependent effects of CaMKIV were observed on the formation of LTP as well as memory, suggesting that the ability to form LTP may contribute to LTM formation. However, we cannot exclude fecting learning and recent memory. Moreover, previous studies suggest dose-dependent effects for CaMKIV on memory formation; genetic disruption of the CaMKIV gene impaired recent memory (Ho et al., 2000; Wei et al., 2002), whereas partial inhi- 
bition of CaMKIV by the forebrain expression of dominantnegative CaMKIV impaired persistent memory without affecting recent memory (Kang et al., 2001). In the present study, aged WT mice failed to form persistent memory ( $\sim 3$ weeks $)$ but exhibited normal recent memory $(\sim 1 \mathrm{~d})$ of passive avoidance. Importantly, the overexpression of CaMKIV prevented this deficit. It is possible that this prevention reflects the overexpression of CaMKIV in the cortex of transgenic mice. Collectively, these findings raise the possibility that, as with $\alpha$ CaMKII, CaMKIV contributes to the consolidation of remote memory, as well as recent memory. However, the effects of CaMKIV overexpression on memory formation differed in terms of mouse age and testing paradigms. These differences might reflect multiple levels of complexity such as differences in training conditions and differential expression levels of transgenic CaMKIV in various forebrain areas. Additional studies are now required to compare the dose-dependent effects of CaMKIV on the formation of recent and remote memories.

CaMKIV has been shown to function as an upstream kinase of CREB and CBP (Chrivia et al., 1993; Mathews et al., 1994; Bito et al., 1996; Sun et al., 1996; Deisseroth et al., 1998; Korzus et al., 2004). Consistent with this view is that the genetic inhibition of CaMKIV, CREB, or CBP, disrupts memory consolidation and LTP (Yin et al., 1994; Lu et al., 1999; Ho et al., 2000; Ribar et al., 2000; Kang et al., 2001; Kida et al., 2002; Pittenger et al., 2002; Wei et al., 2002; Korzus et al., 2004; Mouravlev et al., 2006). Our findings, showing that the overexpression of CaMKIV leads to improvement of memory consolidation and LTP that is paralleled by increased levels of CREB activation in hippocampus, strongly support the critical contribution of the CaMKIV-CRE$\mathrm{B}-\mathrm{CBP}$ signaling pathway to memory consolidation and LTP. To further understand the impact of this signaling pathway on memory formation and long-term synaptic plasticity, it is now important to investigate the effects of increased CREB and CBP activities on memory formation.

\section{References}

Abel T, Nguyen PV, Barad M, Deuel TA, Kandel ER, Bourtchouladze R (1997) Genetic demonstration of a role for PKA in the late phase of LTP and in hippocampus-based long-term memory. Cell 88:615-626.

Alarcón JM, Malleret G, Touzani K, Vronskaya S, Ishii S, Kandel ER, Barco A (2004) Chromatin acetylation, memory, and LTP are impaired in $\mathrm{CBP}+/-$ mice: a model for the cognitive deficit in Rubinstein-Taybi syndrome and its amelioration. Neuron 42:947-959.

Anagnostaras SG, Maren S, Fanselow MS (1999) Temporally graded retrograde amnesia of contextual fear after hippocampus damage in rat: within-subjects examination. J Neurosci 19:1106-1114.

Anagnostaras SG, Josselyn SA, Frankland PW, Silva AJ (2000) Computerassisted behavioral assessment of Pavlovian fear conditioning in mice. Learn Mem 7:58-72.

Anagnostaras SG, Gale GD, Fanselow MS (2001) Hippocampus and contextual fear conditioning: recent controversies and advances. Hippocampus 11:8-17.

Bach ME, Barad M, Son H, Zhuo M, Lu YF, Shih R, Mansuy I, Hawkins RD, Kandel ER (1999) Age-related defects in spatial memory are correlated with defects in the late phase of hippocampal long-term potentiation in vitro and are attenuated by drugs that enhance the cAMP signaling pathway. Proc Natl Acad Sci U S A 96:5280-5285.

Barnes CA (1979) Memory deficits associated with senescence: a neurophysiological and behavioral study in the rat. J Comp Physiol Psychol 93:74-104.

Berman DE, Dudai Y (2001) Memory extinction, learning anew, and learning the new: dissociations in the molecular machinery of learning in cortex. Science 291:2417-2419.

Bito H, Deisseroth K, Tsien RW (1996) CREB phosphorylation and dephosphorylation: $\mathrm{a} \mathrm{Ca}^{2+}$ - and stimulus duration-dependent switch for hippocampal gene expression. Cell 87:1203-1214.
Bliss TV, Collingridge GL (1993) A synaptic model of memory: long-term potentiation in the hippocampus. Nature 361:31-39.

Bourtchuladze R, Frenguelli B, Blendy J, Cioffi D, Schutz G, Silva AJ (1994) Deficient long-term memory in mice with a targeted mutation of the cAMP-responsive element-binding protein. Cell 79:59-68.

Brightwell JJ, Gallagher M, Colombo PJ (2004) Hippocampal CREB1 but not CREB2 is decreased in aged rats with spatial memory impairments. Neurobiol Learn Mem 81:19-26.

Callaerts-Vegh Z, Beckers T, Ball SM, Baeyens F, Callaerts PF, Cryan JF, Molnar E, D’Hooge R (2006) Concomitant deficits in working memory and fear extinction are functionally dissociated from reduced anxiety in metabotropic glutamate receptor 7-deficient mice. J Neurosci 26:6573-6582.

Chawla S, Hardingham GE, Quinn DR, Bading H (1998) CBP: a signalregulated transcriptional coactivator controlled by nuclear calcium and CaM kinase IV. Science 281:1505-1509.

Chrivia JC, Kwok RP, Lamb N, Hagiwara M, Montminy MR, Goodman RH (1993) Phosphorylated CREB binds specifically to the nuclear protein CBP. Nature 365:855-859.

Creager R, Dunwiddie T, Lynch G (1980) Paired-pulse and frequency facilitation in the CAl region of the in vitro rat hippocampus. J Physiol 299:409-424.

Davis HP, Squire LR (1984) Protein synthesis and memory. Psychol Bull 96:518-559.

Deisseroth K, Heist EK, Tsien RW (1998) Translocation of calmodulin to the nucleus supports CREB phosphorylation in hippocampal neurons. Nature 392:198-202.

Eichenbaum H, Otto T, Cohen NJ (1994) Two functional components of the hippocampal memory system. Behav Brain Sci 17:449-518.

Erickson CA, Barnes CA (2003) The neurobiology of memory changes in normal aging. Exp Gerontol 38:61-69.

Flexner LB, Flexner JB, Stellar E (1965) Memory and cerebral protein synthesis in mice as affected by graded amounts of protein. Exp Neurol $13: 264-272$.

Frankland PW, O’Brien C, Ohno M, Kirkwood A, Silva AJ (2001) $\alpha$-CaMKII-dependent plasticity in the cortex is required for permanent memory. Nature 411:309-313.

Frey U, Morris RG (1998) Weak before strong: dissociating synaptic tagging and plasticity-factor accounts of late-LTP. Neuropharmacology 37:545-552.

Gallagher M, Rapp PR (1997) The use of animal models to study the effects of aging on cognition. Annu Rev Psychol 43:339-370.

Ho N, Liauw JA, Blaeser F, Wei F, Hanissian S, Muglia LM, Wozniak DF, Nardi A, Arvin KL, Holtzman DM, Linden DJ, Zhuo M, Muglia LJ, Chatila TA (2000) Impaired synaptic plasticity and cAMP responsive element-binding protein activation in $\mathrm{Ca}^{2+} /$ calmodulin-dependent protein kinase type IV/Gr-deficient mice. J Neurosci 20:6459-6472.

Hosoda H, Motohashi J, Kato H, Masushige S, Kida S (2004) A BMAL1 mutant with arginine 91 substituted with alanine acts as a dominant negative inhibitor. Gene 338:235-241.

Huang YY, Nguyen PV, Abel T, Kandel ER (1996) Long-lasting form of synaptic potentiation in the mammalian hippocampus. Learn Mem 3:74-85.

Impey S, Smith DM, Obrietan K, Donahue R, Wade C, Storm DR (1998) Stimulation of cAMP response element (CRE)-mediated transcription during contextual learning. Nat Neurosci 1:595-601.

Impey S, Fong AL, Wang Y, Cardinaux JR, Fass DM, Obrietan K, Wayman GA, Storm DR, Soderling TR, Goodman RH (2002) Phosphorylation of CBP mediates transcriptional activation by neural activity and CaM kinase IV. Neuron 34:235-244.

Jensen KF, Ohmstede CA, Fisher RS, Sahyoun N (1991) Nuclear and axonal localization of $\mathrm{Ca}^{2+} /$ calmodulin-dependent protein kinase type $\mathrm{Gr}$ in rat cerebellar cortex. Proc Natl Acad Sci U S A 88:2850-2853.

Josselyn SA, Kida S, Silva AJ (2004) Inducible repression of CREB function disrupts amygdala-dependent memory. Neurobiol Learn Mem 82:159-163.

Kang H, Sun LD, Atkins CM, Soderling TR, Wilson MA, Tonegawa S (2001) An important role of neural activity-dependent CaMKIV signaling in the consolidation of long-term memory. Cell 106:771-783.

Kida S, Josselyn SA, Ortiz SP, Kogan JH, Chevere I, Masushige S, Silva AJ (2002) CREB required for the stability of new and reactivated fear memories. Nat Neurosci 5:348-355. 
Kim JJ, Fanselow MS (1992) Modality-specific retrograde amnesia of fear. Science 256:675-677.

Kogan JH, Frankland PW, Silva AJ (2000) Long-term memory underlying hippocampus-dependent social recognition in mice. Hippocampus $10: 47-56$

Korzus E, Rosenfeld MG, Mayford M (2004) CBP histone acetyltransferase activity is a critical component of memory consolidation. Neuron 42:961-972.

LeDoux JE (2000) Emotion circuits in the brain. Annu Rev Neurosci 23:155-184.

Lu T, Pan Y, Kao SY, Li C, Kohane I, Chan J, Yankner BA (2004) Gene regulation and DNA damage in the ageing human brain. Nature 429:883-891.

Lu YF, Kandel ER, Hawkins RD (1999) Nitric oxide signaling contributes to late-phase LTP and CREB phosphorylation in the hippocampus. J Neurosci 19:10250-10261.

Lynch MA (2004) Long-term potentiation and memory. Physiol Rev 84:87-136.

Malenka RC (2003) The long-term potential of LTP. Nat Rev Neurosci 4:923-926.

Marie H, Morishita W, Yu X, Calakos N, Malenka RC (2005) Generation of silent synapses by acute in vivo expression of CaMKIV and CREB. Neuron 45:741-752.

Martin SJ, Grimwood PD, Morris RG (2000) Synaptic plasticity and memory: an evaluation of the hypothesis. Annu Rev Neurosci 23:649-711.

Matthews RP, Guthrie CR, Wailes LM, Zhao X, Means AR, McKnight GS (1994) Calcium/calmodulin-dependent protein kinase types II and IV differentially regulate CREB-dependent gene expression. Mol Cell Biol 14:6107-6116.

Mayford M, Baranes D, Podsypanina K, Kandel ER (1996) The 3 -untranslated region of CaMKII $\alpha$ is a cis-acting signal for the localization and translation of mRNA in dendrites. Proc Natl Acad Sci U S A 93:13250-13255.

McClelland JL, McNaughton BL, O'Reilly RC (1995) Why there are complementary learning systems in the hippocampus and neocortex: insights from the successes and failures of connectionist models of learning and memory. Psychol Rev 102:419-457.

McGaugh JL (2000) Memory-a century of consolidation. Science 287:248-251.

Mouravlev A, Dunning J, Young D, During MJ (2006) Somatic gene transfer of cAMP response element-binding protein attenuates memory impairement in aging rats. Proc Natl Acad Sci U S A 103:4705-4710.

Nakamura Y, Okuno S, Sato F, Fujisawa H (1995) An immunohistochemical study of $\mathrm{Ca}^{2+} /$ calmodulin-dependent protein kinase IV in the rat central nervous system: light and electron microscopic observations. Neuroscience 68:181-194.

Nguyen PV, Abel T, Kandel ER (1994) Requirement of a critical period of transcription for induction of a late phase of LTP. Science 265:1104-1107.

Oike Y, Hata A, Mamiya T, Kaname T, Noda Y, Suzuki M, Yasue H, Nabeshima T, Araki K, Yamamura K (1999) Truncated CBP protein leads to classical Rubinstein-Taybi syndrome phenotypes in mice: implications for a dominant-negative mechanism. Hum Mol Genet 8:387-396.

Perlmutter M, Metzger R, Nezworski T, Miller K (1981) Spatial and temporal memory in 20 to 60 year olds. J. Gerontol 36:59-65.
Pittenger C, Huang YY, Paletzki RF, Bourtchouladze R, Scanlin H, Vronskaya S, Kandel ER (2002) Reversible inhibition of CREB/ATF transcription factors in region CA1 of the dorsal hippocampus disrupts hippocampusdependent spatial memory. Neuron 34:447-462.

Quevedo J, Vianna MR, Roesler R, de-Paris F, Izquierdo I, Rose SP (1999) Two time windows of anisomycin-induced amnesia for inhibitory avoidance training in rats: protection from amnesia by pretraining but not pre-exposure to the task apparatus. Learn Mem 6:600-607.

Ribar TJ, Rodriguiz RM, Khiroug L, Wetsel WC, Augustine GJ, Means AR (2000) Cerebellar defects in $\mathrm{Ca}^{2+} /$ calmodulin kinase IV-deficient mice. J Neurosci 20:RC107(1-5).

Sheng M, Thompson MA, Greenberg ME (1991) CREB: a Ca ${ }^{2+}$-regulated transcription factor phosphorylated by calmodulin-dependent kinases. Science 252:1427-1430.

Silva AJ, Stevens CF, Tonegawa S, Wang Y (1992) Deficient hippocampal long-term potentiation in alpha-calcium-calmodulin kinase II mutant mice. Science 92:201-206.

Silva AJ, Kogan JH, Frankland PW, Kida S (1998) CREB and memory. Annu Rev Neurosci 21:127-148.

Squire LR, Alvarez P (1995) Retrograde amnesia and memory consolidation: a neurobiological perspective. Curr Opin Neurobiol 5:169-177.

Sun P, Lou L, Maurer RA (1996) Regulation of activating transcription factor 1 and the cAMP response element-binding protein by $\mathrm{Ca}^{2+} /$ calmodulin-dependent protein kinase type I, II, and IV. J Biol Chem 271:3066-3073.

Suzuki A, Mukawa T, Tsukagoshi A, Frankland PW, Kida S (2008) Activation of LVGCCs and CB1 receptors required for destabilization of reactivated contextual fear memories. Learn Mem 15:426-433.

Thor DH, Holloway WR (1982) Social memory of the male laboratory rat. J Comp Physiol Psychol 96:1000-1006.

Uchida S, Sakai S, Furuichi T, Hosoda H, Toyota K, Ishii T, Kitamoto A, Sekine M, Koike K, Masushige S, Murphy G, Silva AJ, Kida S (2006) Tight regulation of transgene expression by tetracycline-dependent activator and repressor in brain. Genes Brain Behav 1:96-106.

Uttl B, Graf P (1993) Episodic spatial memory in adulthood. Psychol Aging 8:257-273.

Watabe AM, Zaki PA, O'Dell TJ (2000) Coactivation of $\beta$-adrenergic and cholinergic receptors enhances the induction of long-term potentiation and synergistically activates mitogen-activated protein kinase in the hippocampal CA1 region. J Neurosci 20:5924-5931.

Wei F, Qiu CH, Liauw J, Robinson DA, Ho N, Chatila T, Zhuo M (2002) Calucium-calmodulin-dependent protein kinase IV is required for fear memory. Nat Neurosci 5:573-579.

Wu LJ, Zhang XH, Fukushima H, Zhang F, Wang H, Toyoda H, Li BM, Kida S, Zhuo M (2008) Genetic enhancement of trace fear memory and cingulate potentiation in mice overexpressing $\mathrm{Ca}^{2+} /$ calmodulin-dependent protein kinase IV. Eur J Neurosci 8:1923-1932.

Yin JC, Wallach JS, Del Vecchio M, Wilder EL, Zhou H, Quinn WG, Tully T (1994) Induction of a dominant negative CREB transgene specifically blocks long-term memory in Drosophila. Cell 79:49-58.

Zhao MG, Toyoda H, Lee YS, Wu LJ, Ko SW, Zhang XH, Jia Y, Shum F, Xu H, Li BM, Kaang BK, Zhuo M (2005) Roles of NMDA NR2B subtype receptor in prefrontal long-term potentiation and contextual fear memory. Neuron 47:859-872. 